\title{
Benefits of, and barriers to, reactivating dormant trials
}

\author{
Ruth Gilbert professor of clinical epidemiology ${ }^{1}$, Katie Harron research fellow in statistics ${ }^{2}$, Lorraine \\ Dearden professor of economics and social statistics ${ }^{3}$
}

${ }^{1}$ UCL Institute of Child Health, London WC1N 1EH, UK; ${ }^{2}$ London School of Hygiene and Tropical Medicine, London, UK; ${ }^{3}$ UCL Institute of Education, London, UK

The UK should follow Ontario and reactivate its treasure trove of dormant trials to generate new science through linkage with administrative data. ${ }^{1}$ Many groups stand to benefit. For example, drug regulators could encourage linkage of dormant and new trials to administrative data to monitor long term safety of drugs. ${ }^{2}$ Linkage would also lead to better evidence on the long term effects of interventions in early life. For example, trials in the 1980s and 1990s led to early enriched nutrition for preterm babies worldwide, but uncertainty about whether cognitive benefits outweigh cardiovascular harms can be resolved only through linkage to administrative data in adolescence and adulthood from health, education, and employment sectors. ${ }^{34}$ So what are the barriers to reactivating dormant trials in the UK? Firstly, cost. Access to primary care data on $10 \%$ of the population held in the Clinical Practice Research Datalink costs six figure sums each year. Few researchers, apart from those in the commercial sector, can afford the data. Second is capacity. Hospital data for England are more affordable than data from primary care but the Health and Social Care Information Centre currently has a backlog of more than 200 applications. ${ }^{5}$ Each week it receives more applications than it processes.

The third barrier is the requirement for consent to link data to dormant trials. Trials from the 1980s and 1990s did not ask for consent to link to administrative data 30 years later. But rules to safeguard privacy might prevent benefits for society. ${ }^{6}$ Ontario is reviewing its policies to make better use of past investments by trial participants and research funders. The UK should do the same. Connecting rigorous science to data from public services will reap benefits far beyond the original trial questions.

Competing interests: None declared.

Full response at: http://www.bmj.com/content/351/bmj.h4601/rr.

1. Henry D, Fitzpatrick T. Liberating the data from clinical trials. BMJ 2015;351:h4601. (16 September.)

2 Harron K, Gamble C, Gilbert R. E-health data to support and enhance randomised controlled trials in the United Kingdom. Clin Trials 2014;12:180-2.

3 Isaacs EB, Ross S, Kennedy D, et al. 10-year cognition in preterms after random assignment to fatty acid supplementation in infancy. Pediatrics 2011:128.e890-8. Kennedy K, Ross S, Isaacs EB, et al. The 10-year follow-up of a randomized trial of long-chain polyunsaturated fatty acid supplementation in preterm infants: effects on growth and blood pressure. Arch Dis Child 2010;95:588-95.

5 Health and Social Care Information Centre. Data access request service dashboard. Data application position. www.hscic.gov.uk/dars-dashboard.

6 Allen J, Holman CD, Meslin EM, et al. Privacy protectionism and health information: is there any redress for harms to health? J Law Med 2013;21:473-85. 